\title{
The Effect of High Loaded Multiwall Carbon Nanotubes in Natural Rubber and Their Nonlinear Material Constants
}

\author{
Natarajan Elango, ${ }^{1}$ N. Srinivasa Gupta, ${ }^{2}$ Yu Lih Jiun, ${ }^{1}$ and Alireza Golshahr ${ }^{1}$ \\ ${ }^{1}$ Faculty of Engineering, UCSI University, 56000 Kuala Lumpur, Malaysia \\ ${ }^{2}$ School of Mechanical Engineering, VIT University, Vellore, India
}

Correspondence should be addressed to Natarajan Elango; cad.elango.n@gmail.com

Received 9 June 2017; Revised 12 August 2017; Accepted 10 September 2017; Published 3 December 2017

Academic Editor: Andrew R. Barron

Copyright ( 2017 Natarajan Elango et al. This is an open access article distributed under the Creative Commons Attribution License, which permits unrestricted use, distribution, and reproduction in any medium, provided the original work is properly cited.

\begin{abstract}
The aim of this paper is to study the high load of multiwall carbon nanotubes (MWCNTs) in natural rubber (NR) matrix. Firstly, the rubber matrix, fillers, and crosslinker are thoroughly mixed together in two-roll mill. Rheological tests are done from which scorch time, cure time, and cure index are estimated. The kneaded mixer is then compression molded, dumb bell samples as per ASTM D412 are prepared, and tensile strength, tensile modulus, elongation at break, and hardness are measured. It is noticed that NR/30\% MWCNT has shown the highest tensile strength of $23.38 \mathrm{MPa}$ and Shore A hardness of 90 , which is $78.18 \%$ and $91.5 \%$, respectively, higher than the unfilled NR. The increase in strength and hardness, the ductility loss, and decrease in elongation at break are observed upon increase in filler. FTIR, SEM, and AFM examinations are done and the results show high dispersion of nanofillers and strong interfacial interaction with rubber, which is responsible for overall enhancement in mechanical properties of the nanocomposites. Furthermore, the nonlinear material constants are evaluated through extended tube model and corresponding nonlinear material constants of different filler compositions are presented for the designers to use them in their component design and analysis.
\end{abstract}

\section{Introduction}

The extent of improvement in material properties mostly depends on the filler size, aspect ratio, state of dispersion, processing technique, and others [1]. Silica $\left(\mathrm{SiO}_{2}\right)$ and carbon black are conventional reinforcing fillers used to improve mechanical properties of various rubbers [2]. The inclusion of small amount of nanofillers may render the resultant composite with great enhancement in modulus and strength. Carbon black filler provides an enhancement in tensile strength, tear strength, elastic modulus, abrasion resistance, and electrical property. The silica filler gives a unique improvement in tear strength, abrasion resistance, aging resistance, and adhesion properties. Nanofillers have recently attracted a huge scientific interests due to resulting high surface-to-volume, high stiffness, low density, high modulus, high damping, and others. Carbon nanotubes (CNTs) and graphene have been used to fabricate polymer nanocomposites to gain improvement in electrical and mechanical properties. The fillers are added to the rubber matrix according to the requirement of material properties. Several methods including solution casting, meltmixing, and in situ polymerization of monomers with presence of CNTs have been attempted to prepare polymer nanocomposites [3-12]. The common method in dispersion of filler in the rubber matrix is sonication in which pulsed ultrasound exfoliates agglomerates and disperses MWCNTs in the rubber matrix. The challenge that the researchers face is synthesizing composite with superior properties. It is because of nonhomogeneous dispersion of CNTs in rubber matrix and low interfacial interaction between them that lead to inefficient load transfer between matrix and the filler.

Zhang et al. [11] reported that the inclusion of $1 \mathrm{wt} \%$ of nanotubes into nylon-6 (PA6) results in about 115\% increase in tensile modulus, $120 \%$ in tensile strength, and $67 \%$ in hardness. Chen et al. [12] attempted to disperse double wall carbon nanotubes (DWCNT) into epoxy resin matrix. Gojny et al. [13] studied the effect of CNTs in thermal conductivity of polymer composite. Rattanasom et al. [2] 
reported the reinforcement of NR with silica/CB hybrid filler at various ratios. $\mathrm{Li}$ et al. [14] attempted to prepare silicone nanocomposites with $1,2,3.5$, and $5 \mathrm{wt} \%$ of MWCNTs and reported that $5 \%$ has enhanced the mechanical property. Takeuchi et al. [15] reported that the reinforcing performance improves as diameter of MWCNT decreases, while thermal resistance improves as heat-treatment temperature decreases. Pinto and Rezende [16] prepared a conducting composite with poly(o-methoxyaniline) (POMA) and CNT of 0.1 and $0.5 \mathrm{wt} \%$ and incorporated them in epoxy resin. They concluded that inclusion of CNTs increased the conductivity of the composite. Li [17] attempted with MWCNTs and hydroxyl (HO) modified MWCNTs to increase the mechanical property of Polypropylene (PP) through twin-screw method. He concluded that $\mathrm{HO}$ modified MWCNT has shown high dispersion than MWCNT. Phomrak and Phisalaphong [18] attempted with bacterial cellulose (BC) to reinforce the NR latex and concluded that the tensile strength was increased 94\% higher than pure NR latex. Medina et al. [19] prepared a glass fiber reinforced composite using CNTs doped epoxy and concluded that incorporation of CNTs increased the hardness by $6 \%$ and decreased the fracture toughness by $17 \%$.

Tarawneh et al. [20] prepared thermoplastic natural rubber composite with MWCNTs through melt blending method. They melt blended polypropylene (PP), NR, and liquid natural rubber (LNR) in a ratio of $70 \%, 20 \%, 10 \%$, respectively, and MWCNTs in the ratio of $1,3,5$, and $7 \mathrm{wt} \%$. They noticed that the mechanical strength increases with 1 and $3 \%$ of MWCNTs and decreases with 5 and $7 \%$ of MWCNTs. Azira et al. [21] attempted with 1, 3, 5, 7, and $10 \mathrm{wt} \%$ of MWCNTs dispersed in toluene by sonicating method and further added natural rubber latex into the solution. They reported that the strength decreases beyond $3 \mathrm{wt} \%$ of MWCNTs. Bokobza [22] also attempted to study mechanical and electrical properties of NR/MWCNT composite through sonication method. He used 1, 2, 3, 5, and $10 \mathrm{wt} \%$ of MWCNTs and reported that there is negative effect in mechanical properties due to filler loading. It is drawn from the above literatures that only a low loading (up to $10 \%$ ) of MWCNTs has been attempted, the mechanical strength was increased up to inclusion $3 \mathrm{wt} \%$ of MWCNTs, and compression molding technique has not been mostly attempted. This research focuses on high loading of MWCNTs into NR matrix through compression molding technique and investigates the effect of fillers in mechanical properties.

\section{Two-Roll Mill Process and Rheological Test}

The fillers, NC7000 ${ }^{\mathrm{TM}}$, used in the current research are thin multiwall carbon nanotubes (MWCNT) produced via the Catalytic Chemical Vapor Deposition (CCVD) process by $\mathrm{NANOCYL}^{\circledR}$, Belgium. They are tube-shaped materials, exclusively composed of carbon atoms, having a nanometric diameter of $9.5 \mathrm{~nm}$, length of $1.5 \mu \mathrm{m}$, and density of $1.3 \mathrm{~g} / \mathrm{cm}^{3}$. They generally look like a black powder and spaghetti like structure at nanoscale. Figure 1 shows TEM image of MWCNT. It is obvious that the addition of different weight fractions of filler prepares nanocomposites with different material properties. Table 1 shows amount of NR and phr
TABLE 1: The amount of NR and MWCNTs.

\begin{tabular}{lccccc}
\hline Description & 1 & 2 & 3 & 4 & 5 \\
\hline Natural rubber (47 Shore A) & 100 & 95 & 90 & 80 & 70 \\
NC7000 MWCNT phr & 0 & 5 & 10 & 20 & 30 \\
$l=1.5 \mu \mathrm{m}, d=9.5 \mathrm{~nm}, \rho=1.3 \mathrm{~g} / \mathrm{cc}$ & & & & & \\
\hline
\end{tabular}

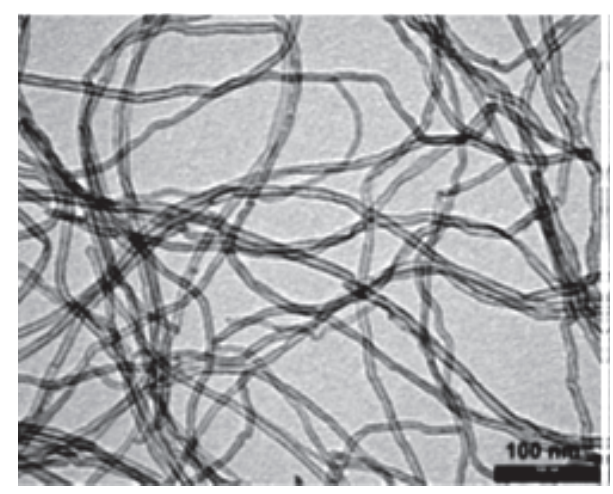

FIGURE 1: TEM image of NC7000 MWCNT_scale: $100 \mathrm{~nm}$.

(parts per hundred units of rubber) of MWCNT used to synthesize NR/MWCNT nanocomposites and Table 2 depicts the mixing cycle of the composite.

Initially, NR of predetermined quantity was wrapped around in a two-roll mill running at $20 \mathrm{rpm}$ with roll gap of $1 \mathrm{~mm}$ for about 20 minutes to render more radicals as the molecular weight decreases. The predetermined quantity of ingredients was slowly added to NR matrix with the roll gap of $0.1 \mathrm{~mm}$ and wrapped further continuously for another 20 minutes. The mixer was then kept at room temperature for 24 hours. In the second stage of mixing, the predetermined quantity of MWCNTs was added to NR kneaded mixer at the roller speed of $20 \mathrm{rpm}$ with $0.1 \mathrm{~mm}$ of roller gap to open up MWCNT aggregates. Sulphur and TMT as accelerators were added to the kneaded mixture to speed up the mastication and the mixing was continued for about 20 minutes to prepare the sheet of $2 \mathrm{~mm}$ thickness. After ensuring the homogeneous mixing of materials through optical microscopy, the rheological tests were carried out in oscillating disc rheometer as per ASTM D 2084-01 (ISO 3417).

The oscillating disc type rheometer is an efficient, simple, and reliable testing machine from which the cure curve is obtained. The "cure curve" is a fingerprint of the compound's vulcanization and processing character. $200 \mathrm{~g}$ of compound in each mixing was considered in the tests. The standard frequency of the rotary oscillation of the disk and temperature were set as $1.7 \mathrm{~Hz}$ and $150^{\circ} \mathrm{C}$, respectively. The following data were measured from the tests:

(a) The minimum torque $(\mathrm{ML})$ which is a measure of the stiffness of the unvulcanized test specimen taken at the lowest point of the curve. It is proportional to the viscosity of the uncured compound.

(b) The highest torque $(\mathrm{MH})$ which is a measure of stiffness or shear modulus of the fully vulcanized test specimen at the vulcanization temperature. 


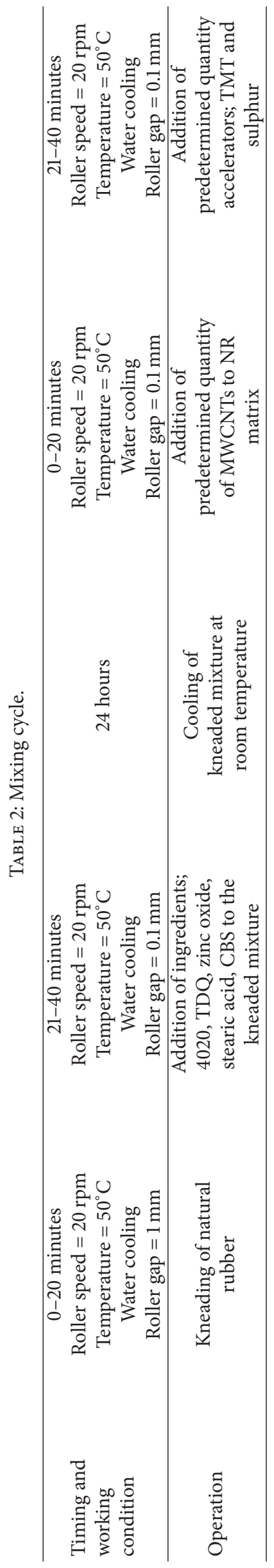




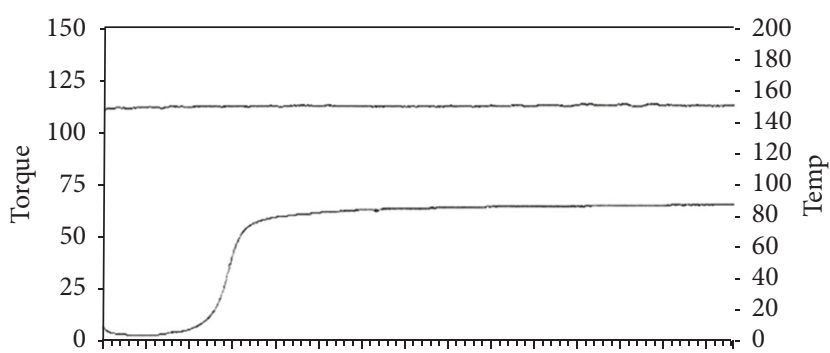

(a) Pure NR

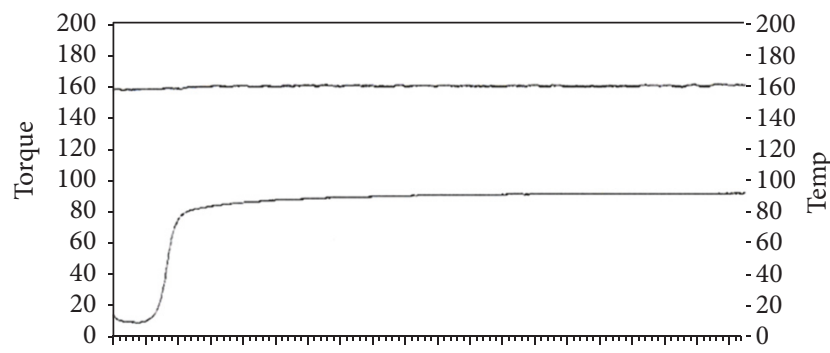

(c) 10 phr MWCNT filled NR

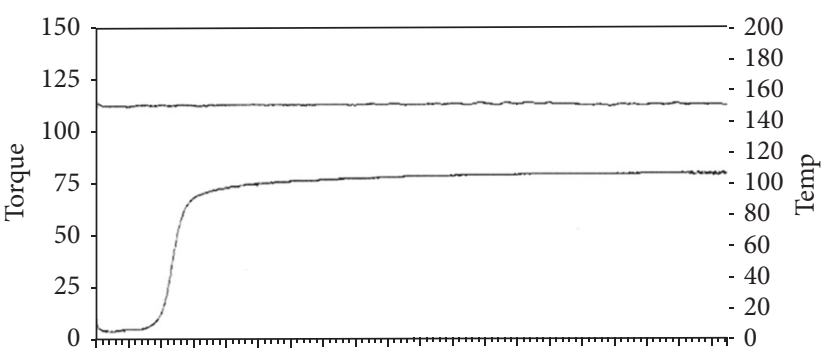

(b) 5 phr MWCNT filled NR

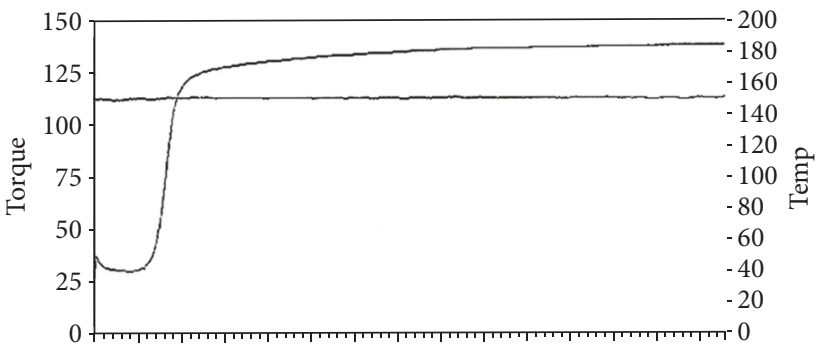

(d) 20 phr MWCNT filled NR

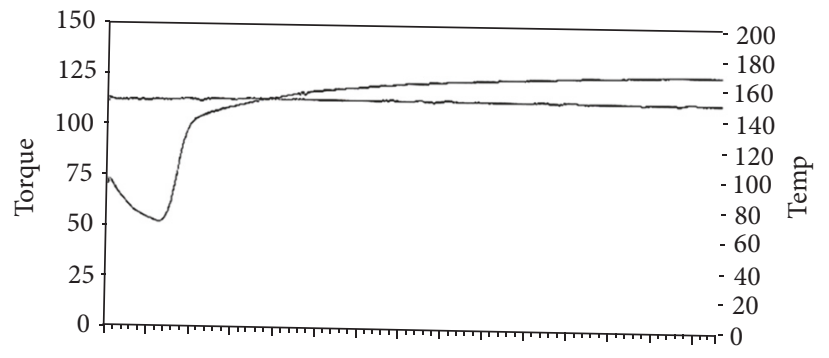

(e) 30 phr MWCNT filled NR

Figure 2: Rheological curves: (a) pure NR, (b) 5 phr MWCNT, (c) 10 phr, (d) 20 phr, and (e) 30 phr.

(c) Induction time (tS2) which is equal to $2 \mathrm{dN} \cdot \mathrm{m}$. It rises above $\mathrm{ML}$ and is used with $3^{\circ}$ amplitudes.

(d) Scorch time (tS5) which is a measure of the time at which vulcanization begins.

(e) The optimum cure time to obtain $50 \%$ of cure, known as tc50.

(f) The optimum cure time to obtain $90 \%$ of cure, known as tc 90 .

(g) Cure rate which is a derived parameter that measures the rate of vulcanization. It is calculated as $C R=100 /(\operatorname{tc} 90-$ ts2).

Table 3 shows the data obtained from rheological tests and Figure 2 shows the rheological curves of the composites. The scorch time is a measure of process safety. A drop of the scorch safety is noticed as a consequence of the addition of MWCNTs in NR matrix. Interestingly, the scorch time is increased in 20 phr and 30 phr samples, regarded as the increase in the process safety. In order to ensure this unexpected phenomenon, the test was repeated two more times and found no change in the results. Scorch time is also considered to be the time at which the vulcanization starts. It is observed from the results that the time at which vulcanization starts depends on the amount of filler added.

The cure rate (CR) index is the rate at which the crosslinking and the development of stiffness of the compound occur after the scorch point. As the compound is heated beyond the scorch point, the properties of the compound change from the soft plastic to a tough elastic material required for use. Cross links are introduced which connect the long polymer chains of the rubber together during the curing phase. As more cross links are introduced, the polymer chains become more firmly connected and the stiffness of the compound increases. It is evidently seen in the difference between maximal and minimal torque. The full curved torque is a measure of shear modulus or stiffness of the compound. From the results of rheology tests, the maximum torque, difference in torque, and cure index are increased due to addition of fillers, which can be regarded as a consequence of an increasing network density. These phenomena show the increase in stiffness of the resultant composite, compared to pure NR. But, there is a drop in maximum torque and torque difference of $30 \mathrm{phr}$ composite compared to $20 \mathrm{phr}$ composite, which is considered to be a loss in stiffness.

\section{Preparation of Samples and Experimental}

The mixer prepared from the two-roll mill process was placed into a mold of $150 \mathrm{~mm} \times 150 \mathrm{~mm} \times 2 \mathrm{~mm}$ dimension. The compression molding was carried out for about 20 minutes at $160^{\circ} \mathrm{C}$ and the slab of size $150 \times 150 \times 2 \mathrm{~mm}$ in each 


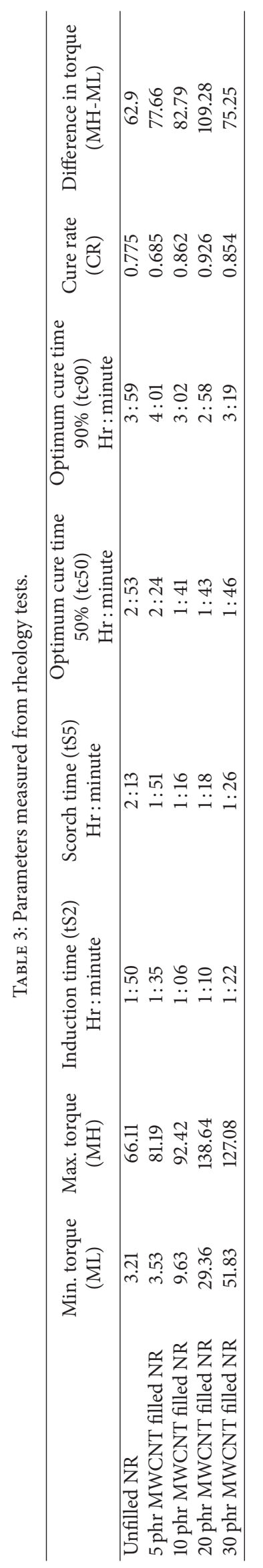


TABLE 4: Repeatability and reproducibility of experimental data.

\begin{tabular}{|c|c|c|c|c|}
\hline & & $\begin{array}{l}\text { Mean tensile strength } \\
\bar{x}=\sum_{1}^{5} x(\mathrm{MPa})\end{array}$ & $\begin{array}{l}\text { Variance } \\
\sum_{1}^{5}(x-\bar{x})\end{array}$ & $\begin{array}{c}\text { Standard deviation } \\
S=\sum_{1}^{5}\left(\left(x-\bar{x}^{2}\right) /(5-1)\right)\end{array}$ \\
\hline \multirow{4}{*}{ NR/5 phr MWCNT } & Machine 1 & 5.6025 & 0.01103 & 0.105002 \\
\hline & Machine 2 & 5.5097 & 0.01493 & 0.122205 \\
\hline & \multicolumn{4}{|c|}{ Average of laboratory average $\dot{x}=5.5561 \mathrm{MPa}$} \\
\hline & \multicolumn{4}{|c|}{ SD of the laboratory averages $S_{\bar{x}}=0.0657$} \\
\hline \multirow{4}{*}{ NR/10 phr MWCNT } & Machine 1 & 7.5198 & 0.01613 & 0.126985 \\
\hline & Machine 2 & 7.5511 & 0.01233 & 0.111058 \\
\hline & \multicolumn{4}{|c|}{ Average of laboratory average $\dot{x}=7.5354 \mathrm{MPa}$} \\
\hline & \multicolumn{4}{|c|}{ SD of the laboratory averages $S_{\bar{x}}=0.0222$} \\
\hline \multirow{4}{*}{ NR/20 phr MWCNT } & Machine 1 & 14.788 & 0.04631 & 0.215192 \\
\hline & Machine 2 & 14.682 & 0.03282 & 0.181159 \\
\hline & \multicolumn{4}{|c|}{ Average of laboratory average $\dot{x}=14.735 \mathrm{MPa}$} \\
\hline & \multicolumn{4}{|c|}{ SD of the laboratory averages $S_{\bar{x}}=0.0753$} \\
\hline \multirow{4}{*}{ NR/30 phr MWCNT } & Machine 1 & 23.385 & 0.04913 & 0.221651 \\
\hline & Machine 2 & 23.317 & 0.05935 & 0.243615 \\
\hline & \multicolumn{4}{|c|}{ Average of laboratory average $\dot{x}=23.351 \mathrm{MPa}$} \\
\hline & \multicolumn{4}{|c|}{ SD of the laboratory averages $S_{\bar{x}}=0.0484$} \\
\hline
\end{tabular}

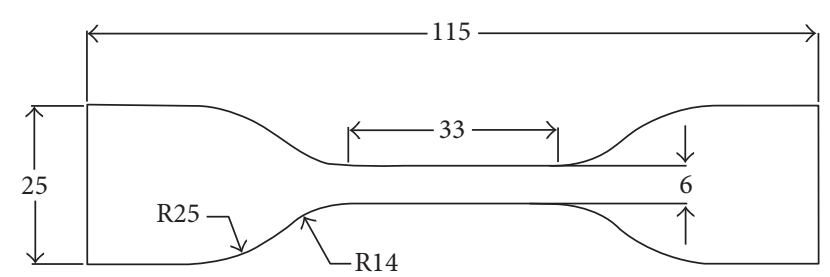

FIgURE 3: Dimensions of dumb bell specimen as per ASTM D41206a (ISO 37) Type C.

composition was prepared. The postcuring was done on the molded slabs for about 4 hours at $200^{\circ} \mathrm{C}$ in a digital oven. The dumb bell samples as per ASTM D412-06a (ISO 37) standard as shown in Figure 3 were then cut from vulcanized nanocomposite slabs. Ductility decrease was observed during high load of fillers. The resultant composite became more brittle and not usable when the weight percentage of filler exceeded $30 \mathrm{phr}$.

The tensile tests were conducted in two different laboratories, but with the same test conditions. The equidistant of $33 \mathrm{~mm}$ from the centre of the sample was marked in each sample and the uniaxial tensile test was conducted in Instron ${ }^{\circledR}$ 3366 universal tensile testing machine in VIT University, India, at quasi-static strain rate of $250 \mathrm{~mm} /$ minute. The tensile modulus, tensile strength, and elongation at break were recorded for each sample. The test was repeated 5 times for each weight fraction to ensure the repeatability of the measured data. The same set of experiments were also conducted in tensile testing machine in Aerospace Engineers Pvt. Ltd., India, to ensure the reproducibility of the measured data. The mean, variance, standard deviation of the measured data, repeatability, and reproducibility are tabulated in Table 4. Repeatability refers to the variability between independent test results obtained within a laboratory with a specific set of testing equipment using random samples. Reproducibility deals with the variability between single test results obtained from different laboratories, each of which has applied the test procedures to random samples. The smaller standard deviation represents the closeness of the measured data to the mean of the measures. The standard deviation of the measured data in each laboratory and the standard deviation of laboratory averages are very small, which ensured the repeatability and reproducibility of the measurements, respectively. The Shore hardness of the resultant composites was measured using type-A durometer as per ASTM 2240.

3.1. Scanning Electron Microscopic (SEM) Examinations. SEM examinations were done on unfractured samples and fractured samples of different weight fractions. It shows good wetting properties between the MWCNTs and rubber matrix for all the unfractured samples. No visible voids nor pull out was observed even for high fiber loading. The rolling process realigned the fiber in a uniform direction and MWCNT was found aggregated in the clumps, scattered randomly in the matrix. Figure 4 shows SEM images taken on unfractured samples at 500x magnification. It seems that the MWCNTs are fibrillated and uniformly distributed and are visible as white spots.

Figure 5 shows the SEM images of cross section of the fractured samples at 10000x. Figure 5(a) shows the fractured cross-sectional surface of the unfilled NR sample. Figures 5(b)-5(e) show the fractured surface of filled NR samples. The MWCNT aggregates as circle marked are seen in the images, particularly more in high fiber loading samples. The crack initiation at fiber aggregates is very visible and pull outs for the fracture are observed. It is persuaded that the effective load transfers from rubber matrix to MWCNT 


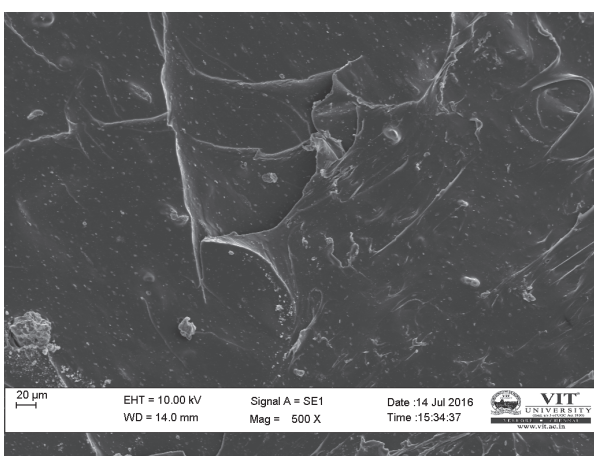

(a) $5 \mathrm{phr}$ MWCNT filled NR

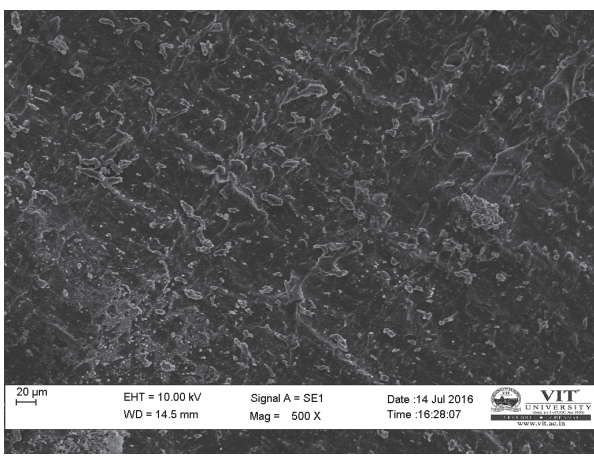

(c) $20 \mathrm{phr}$ MWCNT filled NR

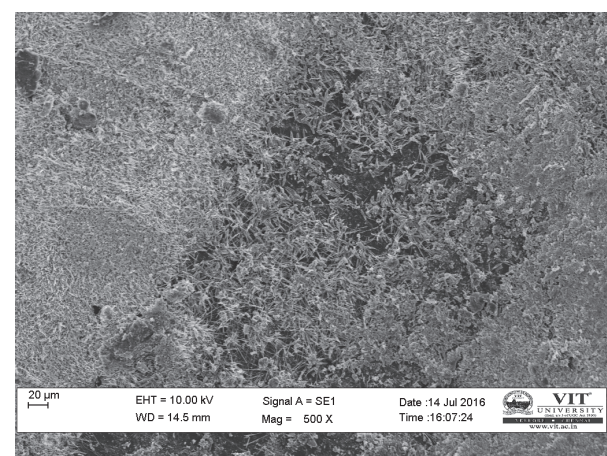

(b) 10 phr MWCNT filled NR

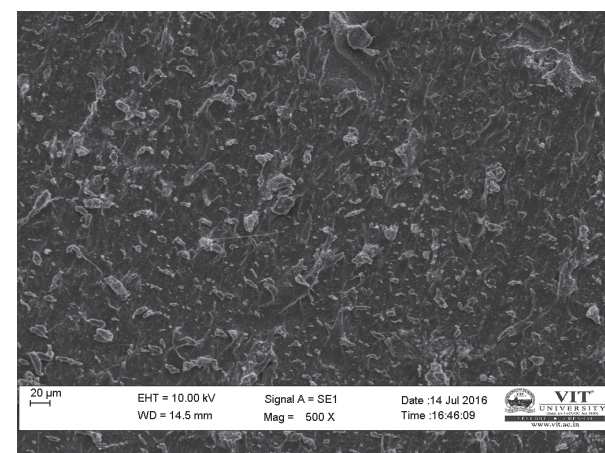

(d) 30 phr MWCNT filled NR

FIgURE 4: SEM images taken on unfractured MWCNTs filled NR samples at 500x.

fibers caused the stress concentrated at the fibers. The fracture surface of MWCNT showed star shape at low magnification, possibly experienced shearing, or friction of fiber-fiber prior to fracture. At higher fiber loading percentage (30 phr), MWCNT became reinforced mesh embedded in the matrix, transferring the elastic rubber matrix favors to brittle behavior. The inefficient load transfers from matrix to MWCNT fibers caused the fracture at matrix.

3.2. Fourier Transform Infrared Spectroscopy (FTIR). The FTIR tests on unfilled NR, MWCNT, and 5, 10, 20, and 30 phr MWCNTs filled samples were carried out in Thermo Scientific ${ }^{\mathrm{TM}}$ Nicolet $^{\mathrm{TM}}$ iN $^{\mathrm{TM}} 10$ Infrared Microscope. The IR spectra of the samples are depicted in Figure 6 and the peak values are tabulated in Table 5. The peak values 455 and $519 \mathrm{~cm}^{-1}$ are observed in MWCNT which represents C$\mathrm{Br}$ stretch bonds. The wave number 2854.14 in NR sample indicates the presence of polyisoprene and other sharp peaks at $1519.18,1443.73,1242,969$, and $829.16=\mathrm{CH}$ stretching vibration, $\mathrm{C}=\mathrm{C}$ stretching vibration, and $=\mathrm{CH}$ have been alterated in all other 5, 10, 20, and 30 phr MWCNTs filled NR samples while the alterations are considerably increased with increase in the percentage of MWCNTs. Accordingly, NR/5 wt\% MWCNT showed the characteristic absorption bands of polyisoprene including the tripeak at 2958, 2916, and $2850 \mathrm{~cm}^{-1}$ corresponding to $\mathrm{CH} 3$ asymmetric stretching vibration, $\mathrm{CH} 2$ asymmetric stretching vibration, and $\mathrm{CH} 2$ symmetric stretching vibration, respectively. Moreover, peaks at 3035,1654 , and $835 \mathrm{~cm}^{-1}$ are attributed to $=\mathrm{CH}$ stretching
TABLE 5: Peak values of IR spectra of samples.

\begin{tabular}{lcc}
\hline Sample & Peak frequency $\left(\mathrm{cm}^{-1}\right)$ & Bond \\
\hline & 2918,2854 & C-H stretch $\left(-\mathrm{CH}_{3}\right)$ \\
& 1600 & C=C stretching \\
Unfilled NR & 1519,1443 & C-H bending $\left(\mathrm{CH}_{3}\right)$ \\
& 1242,1136 & C-H wag $(\mathrm{CH} 2-\mathrm{X})$ \\
& $1032,969,829,754$ & $=\mathrm{C}-\mathrm{H}$ bend \\
& 565 & C-Br stretch \\
\hline MWCNT & 519,455 & C-Br stretch \\
\hline \multirow{3}{*}{ NR/5 phr MWCNT } & 2918,2854 & C-H stretch $\left(-\mathrm{CH}_{3}\right)$ \\
& 1441,1373 & C-H bending $\left(\mathrm{CH}_{3}\right)$ \\
& $973,830,740$ & $=\mathrm{C}-\mathrm{H}$ bend \\
\hline \multirow{2}{*}{ NR/10 phr MWCNT } & 2916,2851 & C-H stretch $\left(-\mathrm{CH}_{3}\right)$ \\
& 1516,1376 & C-H bending $\left(\mathrm{CH}_{3}\right)$ \\
& 968 & $=\mathrm{C}-\mathrm{H}$ bend \\
\hline NR/20 phr MWCNT & 2914 & C-H stretch $\left(-\mathrm{CH}_{3}\right)$ \\
& 1515,1381 & C-H bending $\left(\mathrm{CH}_{3}\right)$ \\
& 1238 & C-H wag $\left(\mathrm{CH}_{2}-\mathrm{X}\right)$ \\
NR/30 phr MWCNT & 965 & =C-H bend \\
\hline & 1510,1378 & C-H bending $\left(\mathrm{CH}_{3}\right)$ \\
& 1233 & $=\mathrm{C}-\mathrm{H}$ bend \\
\hline
\end{tabular}

vibration, $\mathrm{C}=\mathrm{C}$ stretching vibration, and $=\mathrm{CH}$ out-of-plane bending vibration, respectively. It should be noted that absorption bands at 1373 and $1444 \mathrm{~cm}^{-1}$ are assigned to $\mathrm{CH} 3$ 


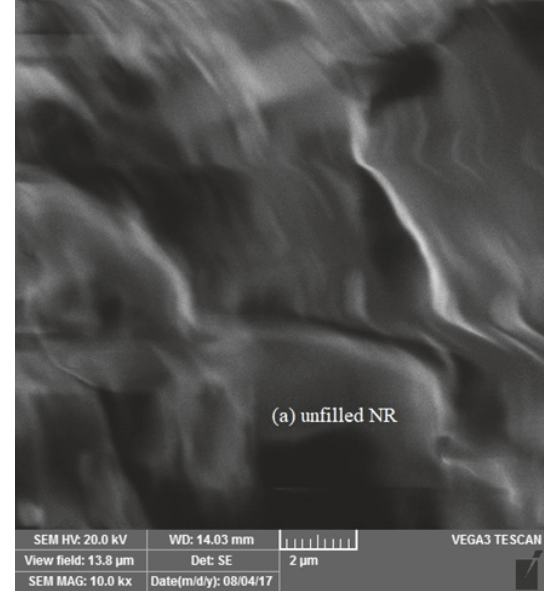

(a)

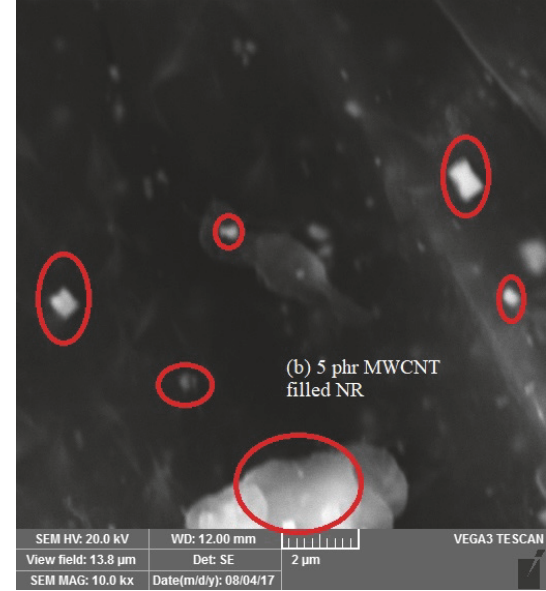

(b)

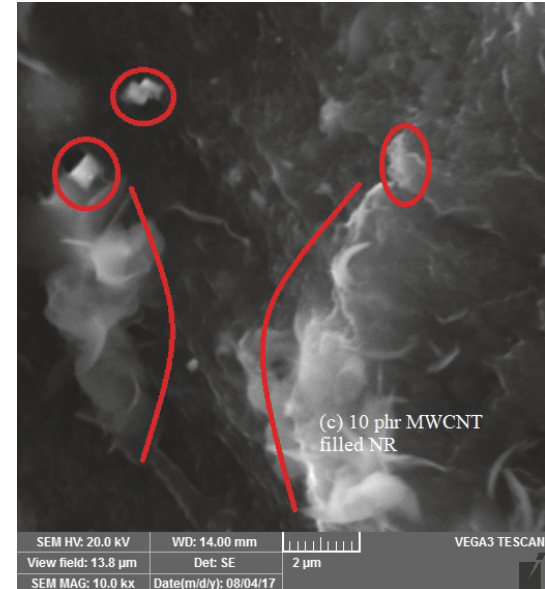

(c)

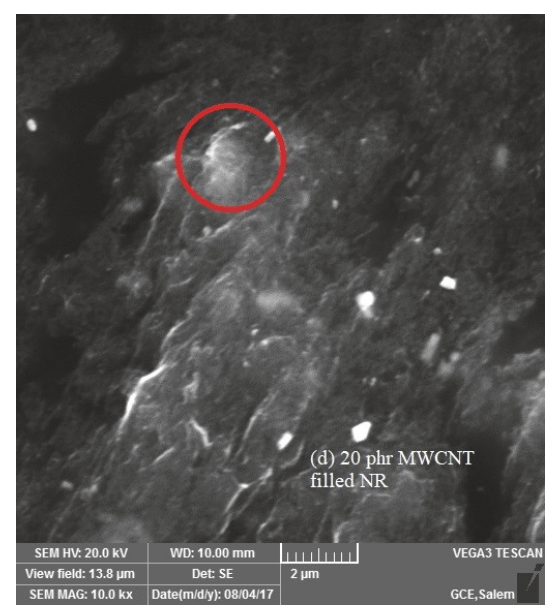

(d)

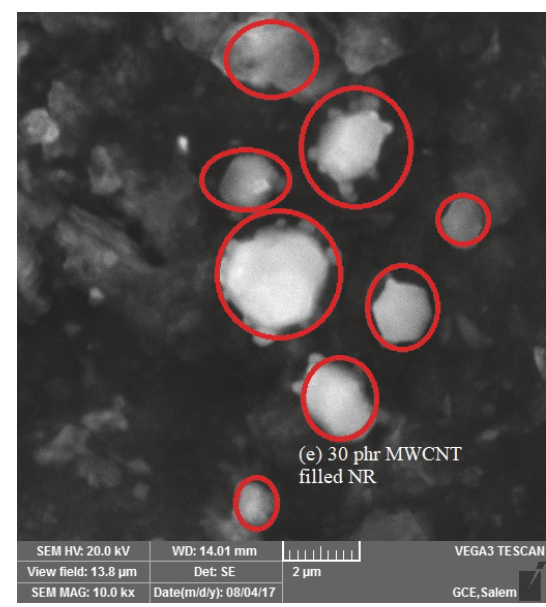

(e)

FIGURE 5: SEM images taken from cross-sectional surface of the fractured (a) unfilled and (b)-(e) MWCNTs filled samples at 10000x.

asymmetric deformation and $\mathrm{CH} 2$ deformation, respectively. Addition of nanocarbon to the polymeric matrix introduced some new absorption bands to the spectrum (specifically distinguishable at higher loading, e.g., $30 \mathrm{phr}$ ) including the peaks at around 1247, 1535, and $1737 \mathrm{~cm}^{-1}$ assigned to $\mathrm{C}=\mathrm{C}$ stretching vibration, stretching vibration of $\mathrm{C}-\mathrm{C}$ bonds of aromatic rings, and $\mathrm{C}=\mathrm{O}$ stretching of aromatic rings, respectively. The mentioned peaks indicate the presence of MWCNTs in the composite. Though significant changes were observed in MWCNTs filled NR, particularly as the filler percentage increases, for further understanding on disruption of carbon filled NR, samples were examined using atomic force microscopy (AFM).

3.3. Atomic Force Microscopic (AFM) Examinations. AFM is one of the most powerful tools for the analysis of surface morphologies as it renders three-dimensional images at angstrom and nanoscale. The qualitative AFM examination was done in Nanosurf easy Scan 2 AFM machine to analyse the dispersion of nanometric fillers in NR matrix. The standard method of rendering AFM data is a two-dimensional (2D) image using a color scale to represent height information. But it is difficult for some viewers to understand the features based on $2 \mathrm{D}$ images. The other way is to render the height information as a pseudo-three-dimensional image. Figure 7 shows 2D and 3D topography of unfilled and filled samples. The white spot as circle marked in the topography line fit images is considered to be MWCNT fiber, which evidently shows the change in phase as arrow marked in topography mean fit images. 3D deflection images show the surface roughness of the samples in terms of peaks and valleys. It is noticed from the deflection images of filled composites that the deflection of the probe is low which is regarded as the high surface finish of the samples. It obvious that the magnitude of deflection is high when the probe detects the fiber or some aggregate. The surface roughness of the sample can be estimated from the sum of the mean of maxima profile valleys depths calculated over the surface and the mean of maxima profile peak height calculated over the surface. The steady peak is almost observed for all filled samples which is regarded to be good wetting of MWCNTs with NR matrix.

3.4. Model of the Filler Reinforced Composite. Einsten equation, Einsten and Guth equation, modified Guth equation, 


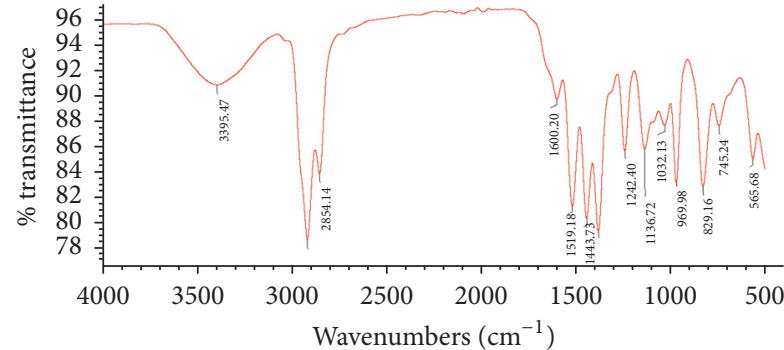

(a) Unfilled NR

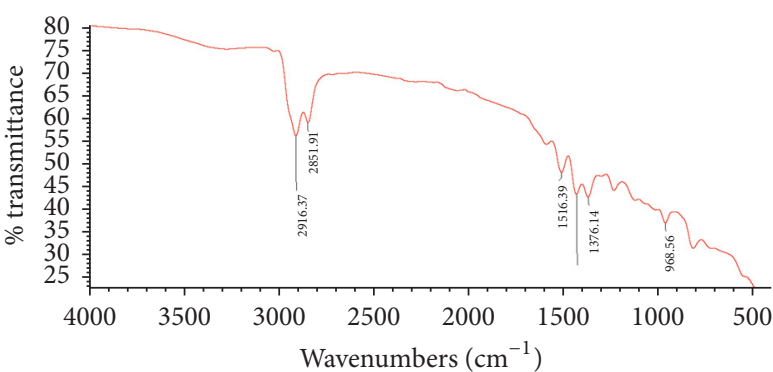

(c) 10 phr MWCNT filled NR

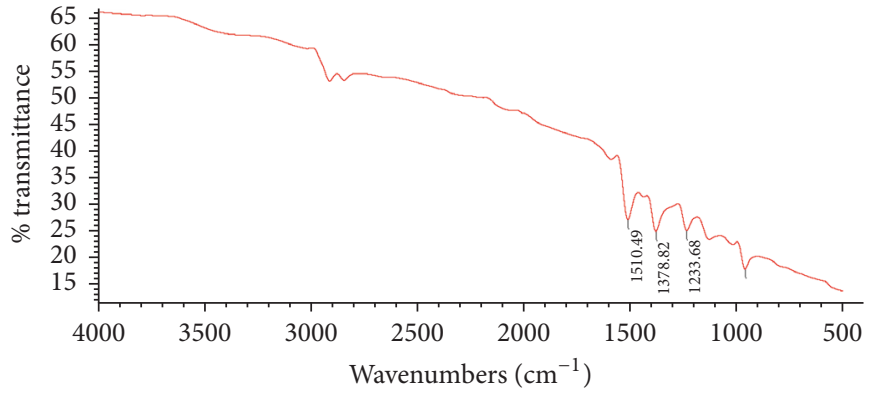

(e) $30 \mathrm{phr}$ MWCNT filled NR

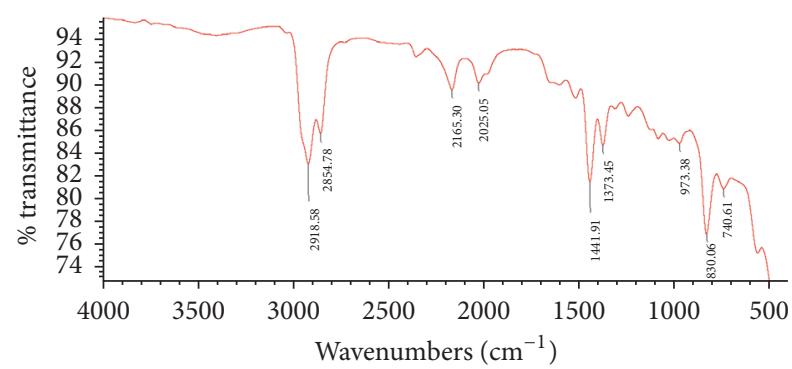

(b) 5 phr MWCNT filled NR

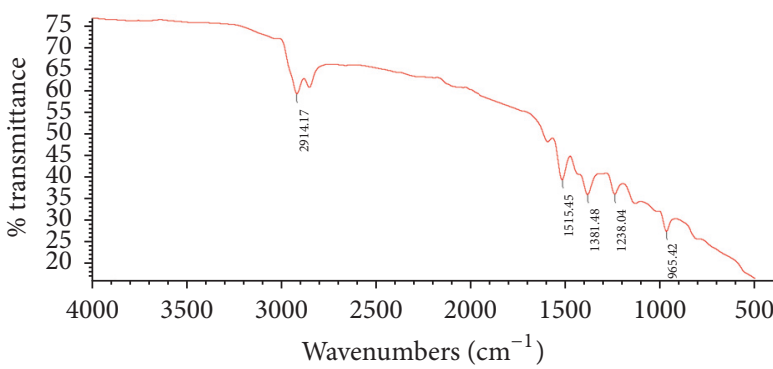

(d) 20 phr MWCNT filled NR

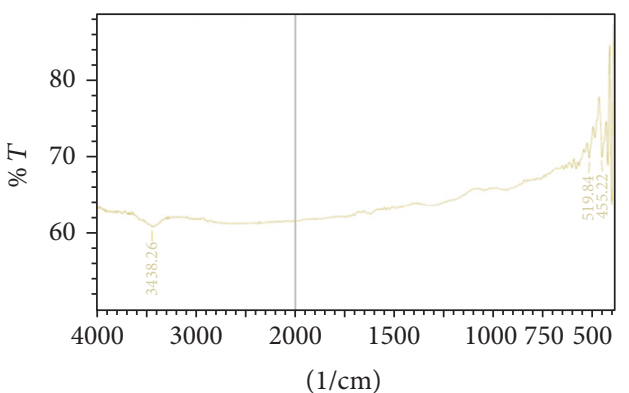

(f) MWCNT

FIgURE 6: FTIR spectrum images taken from (a) unfilled NR sample, (b)-(e) filled NR samples, and (f) MWCNT.

Kerner equation, parallel and series model, Rule of Mixtures model, Hirsch model, Halpin-Tsai model, modified HalpinTsai model, Cox model, and Bowyer and Bader's model are some existing models for evaluating mechanical properties of the composite.

Halpin-Tsai model (H-T model) [23] is a semiempirical model used for aligned fiber reinforced composites. The tensile strength of the composite is predicted as

$$
T_{c}=T_{m} \frac{1+A \eta V_{f}}{1-\eta V_{f}}
$$

where $T_{c}$ is the tensile strength of the resultant composite, $T_{m}$ is the tensile strength of the base matrix, and $T_{f}$ is the tensile strength of the filler. The parameters $\eta$ and $A$ are calculated from Einstein coefficient $K$. The parameter $K$ is calculated from the length $(l)$ and the diameter $(d)$ of the filler.

$$
\begin{aligned}
\eta & =\frac{T_{f} / T_{m}-1}{T_{f} / T_{m}+A}, \\
A & =K-1,
\end{aligned}
$$

$$
K=1+2 \frac{l}{d}
$$

The filler volume fraction $V_{f}$ can be obtained from the weight fraction of the filler, density of the base matrix, and the density of the filler.

$$
V_{f}=\frac{1}{\left[1+\left(\rho_{f} / \rho_{m}\right)\left(1 / W_{f}-1\right)\right]},
$$

where $W_{f}$ is the weight fraction of the filler, $\rho_{f}$ is the density of the filler, and $\rho_{m}$ is the density of the matrix.

Equations (1)-(3) of H-T model were used to predict the tensile strength of filled NR of different weight fractions and further compared with the experimental results.

\section{Extended Tube Model-A Nonlinear Material Model}

The ability to predict the failure of an engineering component depends on two main factors: the choice of material model 

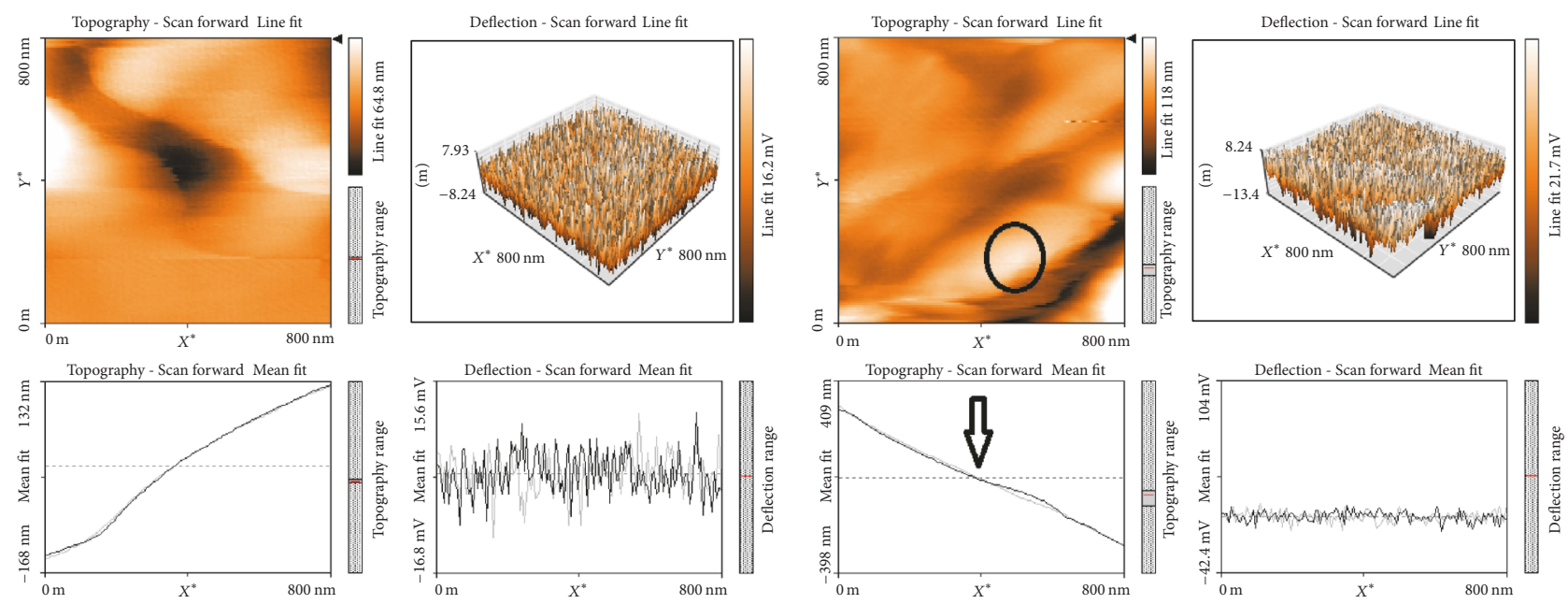

(a) Unfilled NR
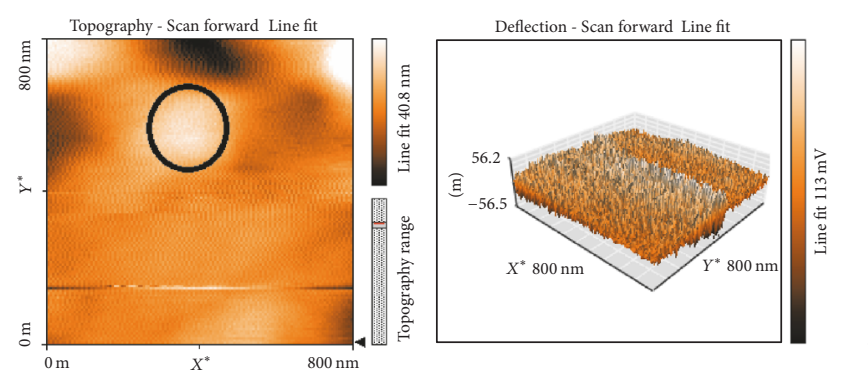

(b) 5 phr MWCNT filled NR

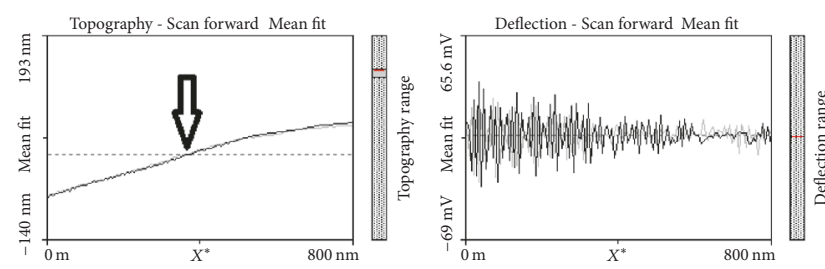

(c) $10 \mathrm{phr}$ MWCNT filled NR
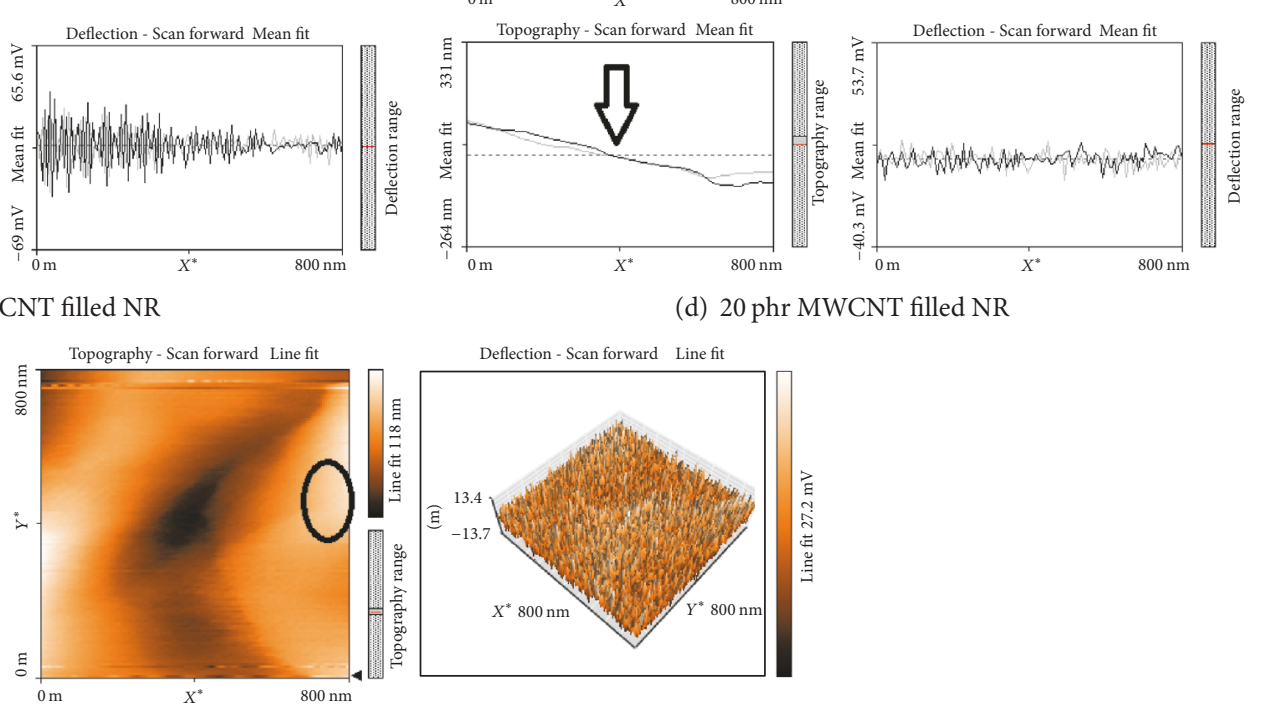

(d) $20 \mathrm{phr}$ MWCNT filled NR

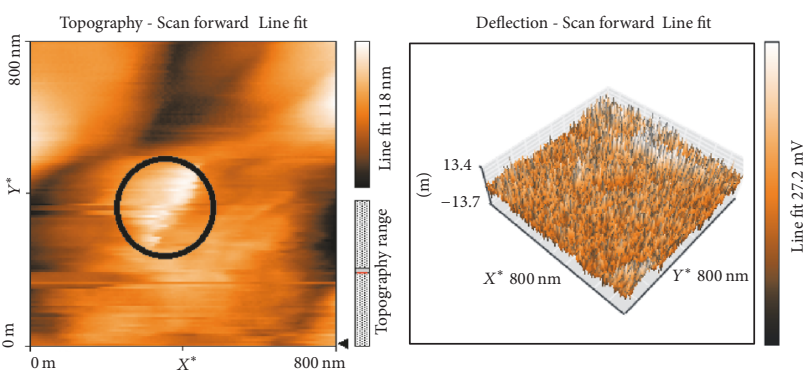

(c)
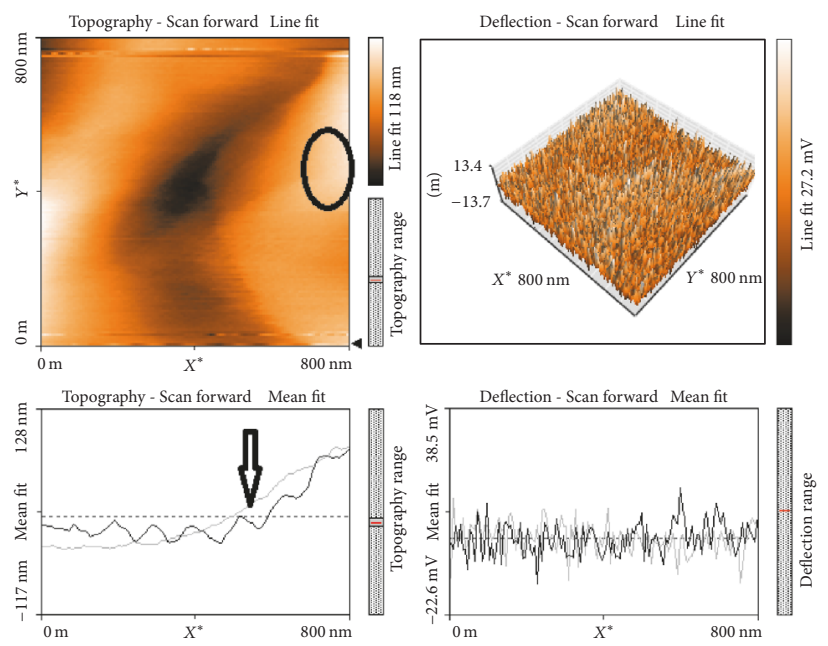

(e) 30 phr MWCNT filled NR

FIGURE 7: AFM images taken on (a) unfilled and (b)-(e) MWCNTs filled samples. 
and the reliability of the data input into the model. Elastomers, biological tissues, rubbers, foams, and polymers are often modelled using hyperelastic models. The hyperelastic materials are special case of Cauchy-elastic material. A hyperelastic model defines the stress-strain relationship using a scalar function-a strain energy density function $(W)$. The strain energy potential can be either a direct function of the principal stretch ratios $W\left(I_{1}, I_{2}, I_{3}\right)$ or a function of the strain invariants, $W\left(\lambda_{1}, \lambda_{2}, \lambda_{3}\right)$. The uniaxial and/or biaxial test as per ASTM standards is to be conducted to obtain stressstrain data for the various load conditions. Curve fit of experimentally measured strain-stress data into the respective hyperelastic material model will result in appropriate material constants of the material. There are many popular nonlinear hyperelastic material models: Mooney-Rivlin [24], Ogden [25], Arruda-Boyce [26], Yeoh [27], Gent [28], and NeoHookean [29]. These models have been used to model soft materials [30-33]. All these characteristic models well suit the unfilled rubber materials that elongate in the range of 100 to 700 .

Kaliske and Heinrich [34] recently proposed a hyperelastic model called extended tube model for filler reinforced rubber composite. The extended tube model is a physicsbased polymer model, which introduces the physical consideration on the molecular scale into the formulation of the strain energy potential. The model considers the topological constraints as well as the limited chain extensibility of network chains in the filled rubbers. The chains are constrained to remain in a tube formed by surrounding chains, referred to as the tube model. This assumption is characterised to the high degree of entanglement of rubber network. In the unfilled polymer networks with elastic characteristics are considered as disordered systems with a constant topology of crosslinks and entanglements. According to theory of elasticity, the crosslinks and entanglements are originated from vulcanization process and they do not change during the deformation process. The filled elastomers show nonlinear stress-strain dependencies, stress softening (Mullins effect), rate dependent inelasticity (Payne effect), and rate independent inelasticity. The framework of this model considers the tube-like topological constraints (packing effects) and finite chain extensibility of the filler reinforced polymer networks. It considers the topology $\mathrm{T}$ given by a set of worm like network chain paths $\mathrm{R}(s)$. The worm like network chain paths are parameterized by the contour variable $s$ and crosslink positions $\mathrm{R}_{i}$, where crosslink positions can be interpreted as average conformations or positions [35]. The readers may refer to $[34,35]$ to further understand the basics of the extended tube model and how the parametrization is being done.

The general form of extended tube model is

$$
\begin{aligned}
W= & \frac{G_{c}}{2}\left[\frac{\left(1-\delta^{2}\right)\left(I_{1}-3\right)}{1-\delta^{2}\left(I_{1}-3\right)}+\ln \left(1-\delta^{2}\left(\left(I_{1}-3\right)\right)\right)\right] \\
& +\frac{2 G_{e}}{\beta^{2}} \sum_{i=1}^{3}\left(\lambda_{i}^{-\beta}-1\right)+\frac{1}{d}(J-1)^{2} .
\end{aligned}
$$

There are 5 material constants involved in this strain energy function. $G_{c}$ represents crosslinked network modulus, $G_{e}$ represents constraint network modulus, $\beta$ is empirical parameter $(0 \leq \beta \leq 1)$, and $\delta$ and $d$ are extensibility and incompressibility parameters, respectively. $\beta$ represents the influence of the global rearrangement of crosslinks upon deformation and in consequence the release of topological constraints. It is physically derived for a given polymer network as a function of the amount of solvent, solution fraction, network defects, and filler and it indicates the completeness of the cross-linking reaction [35]. The incompressible parameter for the rubber material is considered to be zero and hence only four parameters are to be evaluated. The initial shear modulus of the material is given by $G=G_{c}+G_{e}$. Finite element (FE) analysis software such as ANSYS, Marc, and ABACUS provides the options to curve fit the strain-stress data to derive the material constants of different nonlinear models.

Marckmann and Verron [36] conducted a benchmark of twenty hyperelastic models using Treloar's and biaxial extension data obtained experimentally for isoprene rubber vulcanizate. The ranking was done based upon the complexity of their mathematical formulation and ability of accurately reproducing the test data. Gorash et al. [37] conducted a benchmark of all existing hyperelastic models with the experimental data from rubber cylinder under compression proposed by Lindley (1967). Behnke et al. [38] conducted a thermomechanical analysis of critically loaded particlereinforced elastomer component. In all the above case studies, the analytical solution and FEA results of the case study problems were compared. They revealed that extended tube model and response function model are more efficient models than conventional models for filled rubber.

Extended tube model was attempted to evaluate nonlinear material constants of the resultant NR/MWCNT nanocomposites of different weight fraction. The strain-stress data measured from uniaxial tensile tests were input in ANSYS 18.0 APDL and the corresponding nonlinear material constants were computed. Figure 8 shows a curve fit of strainstress data of NR/30 phr MWCNT composite into extended tube model. It seems that the model well matches with the experimental data of the composite.

The nonlinear material constants of different weight fractions of nanocomposites are presented in Table 6. These data can further be used in the soft material-component design and its nonlinear FE analysis.

\section{Results and Discussion}

Figure 9 shows the tensile strength of unfilled NR and NR/MWCNT composites. It is observed from the results that the reinforcement of MWCNTs in NR has shown drastic increase in the mechanical strength and hardness, but decrease in ductility. When more than $30 \mathrm{phr}$ of fillers was added, the green rubber mixer became more brittle, which could not be further vulcanized.

The tensile strength of unfilled NR is observed as $5.1 \mathrm{MPa}$. The inclusion of $5 \mathrm{phr}$ and $10 \mathrm{phr}$ MWCNTs into pure NR has increased its strength by $9.19 \%$ and $32.49 \%$, respectively. 
TABLE 6: Nonlinear material constants and shear modulus of resultant nanocomposites.

\begin{tabular}{lcccc}
\hline \multirow{2}{*}{ phr of MWCNT } & \multicolumn{3}{c}{ Nonlinear material constants of extended tube model } \\
& $G_{c}(\mathrm{MPa})$ & $G_{e}(\mathrm{MPa})$ & $\beta$ & 2.3433769 \\
\hline $5 \%$ & 0.0688528 & 0.8874444 & 0.9976883 & 2.0894656 \\
$10 \%$ & 0.0361318 & 1.890291 & 0.9998763 & 2.0372378 \\
$20 \%$ & 0.0425993 & 2.8320059 & 1.0021289 & 0.0001507 \\
\hline $30 \%$ & 0.2271428 & 3.6135025 & 1.0092816 & \\
\hline
\end{tabular}

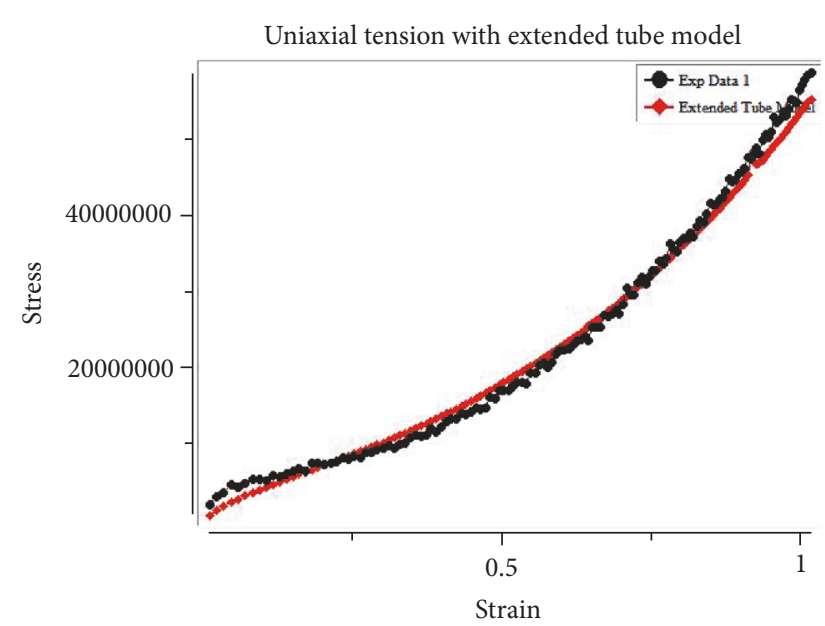

FIgURE 8: Extended tube model curve fit of NR/30 phr MWCNT composite, done in ANSYS 18.0 APDL.

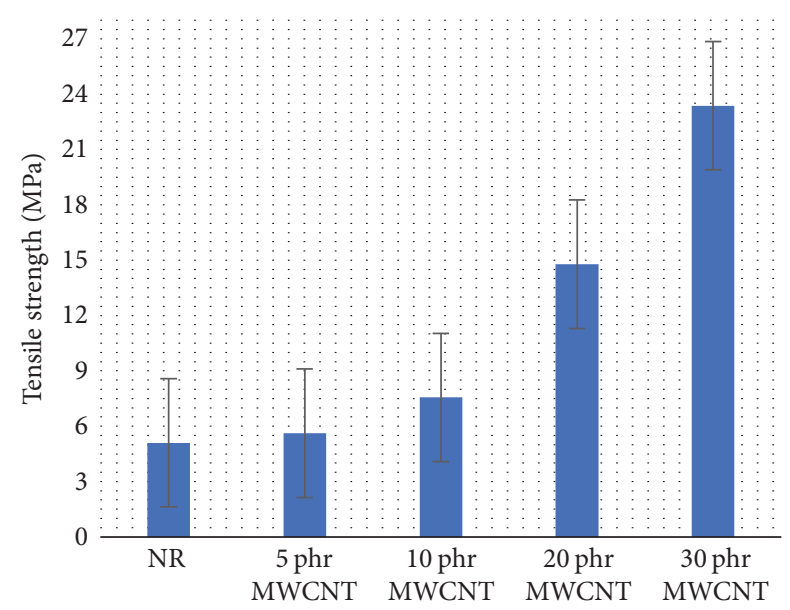

FIGURE 9: Tensile strength of unfilled and filled NR composites.

The adding of $20 \mathrm{phr}$ has increased its strength by $65.49 \%$. The tensile strength of NR/30 phr MWCNTs is observed as $23.38 \mathrm{MPa}$, which is $78.18 \%$ of increase in the mechanical strength. This is in contrast to the results reported by [2022]. In the result of Tarawneh et al. [20] and Azira et al. [21], $1 \%$ and $3 \%$ MWCNTs have increased the mechanical property of NR, but $5 \%, 7 \%$, and $10 \%$ have decreased the mechanical property. In the result of Bakobza [22], the degradation of mechanical property occurred even in a small load of MWCNTs. The degradation of mechanical property could be on

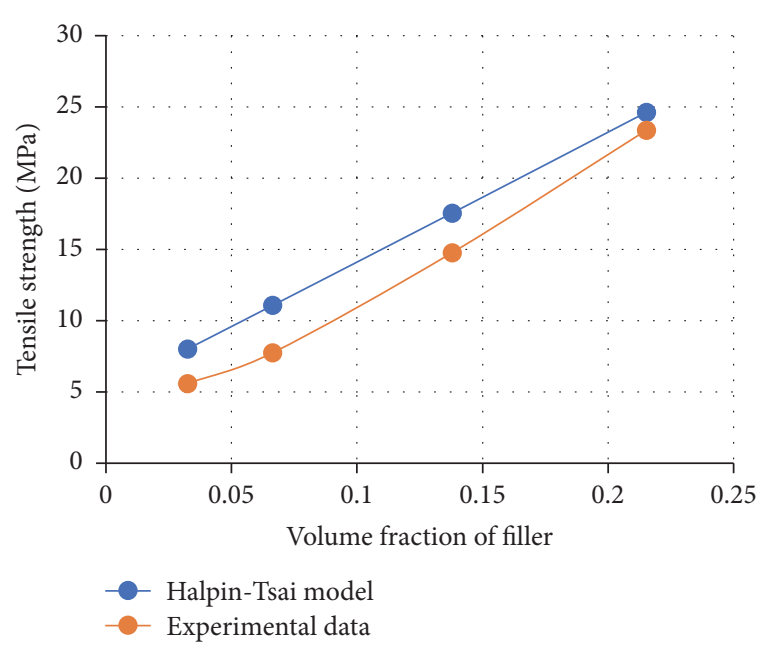

FIgure 10: Comparison of Halpin-Tsai model and experimental results.

account of the presence of some agglomerates. It is interestingly noticed from them that the enhancement of mechanical property of NR is up to $3 \mathrm{wt} \%$ of MWCNT filler, when solution mixing or sonication or melt blending technics are used. But the compression molding process used in this research has given a uniform distribution of filler into NR matrix and increased the mechanical properties very well. The drastic increase in mechanical strength, increase in stiffness, and ductility loss are noticed during the high load of MWCNTs in NR matrix. The similar kind of increase in strength was noticed by Blighe et al. [39], when they high loaded (75 phr) single wall carbon nanotubes (SWCNT) in the silicone rubber matrix. Figure 10 shows the comparison between the predicted tensile strengths from Halpin-Tsai model and the experimental results. The predicted values look close to the experimental results, particularly at higher loaded (30 phr) composite.

The elongation at break of 5, 10, 20, and 30 phr composites is observed as $280,173,169$, and 156 , respectively, as shown in Figure 11. It decreases as expected upon the increase of the fillers. Interestingly noticed from the trend line that the loss of ductility is drastic up to $10 \mathrm{phr}$, beyond which it seems to be minimal. Figure 12 shows the hardness of the resultant nanocomposite against the percentage of filler used. It is observed that Shore A hardness of 30 phr MWCNTs filled NR is 90 , which is about $91.5 \%$ increase compared to unfilled NR. The hardness impart ratio of MWCNT is estimated as 2 for NR matrix. In a nutshell, there is a great improvement in 


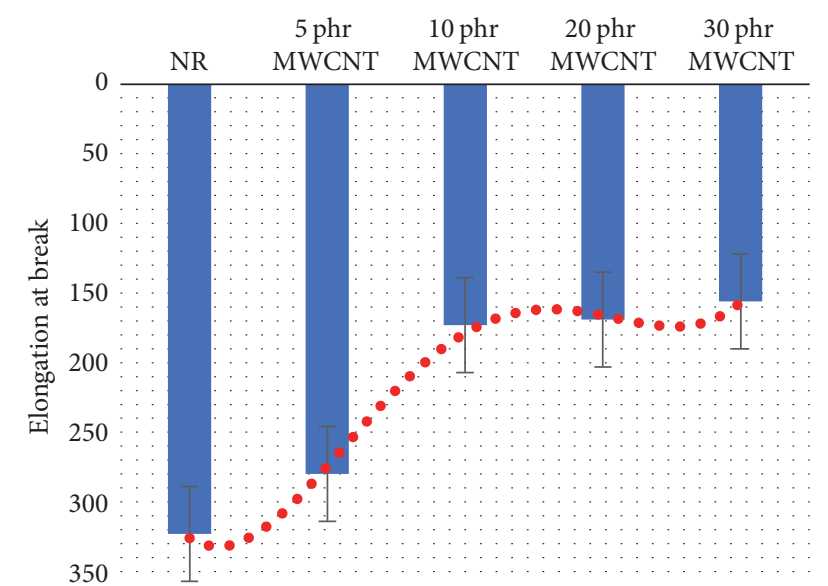

FIGURE 11: Elongation at break against the filler weight percentage.

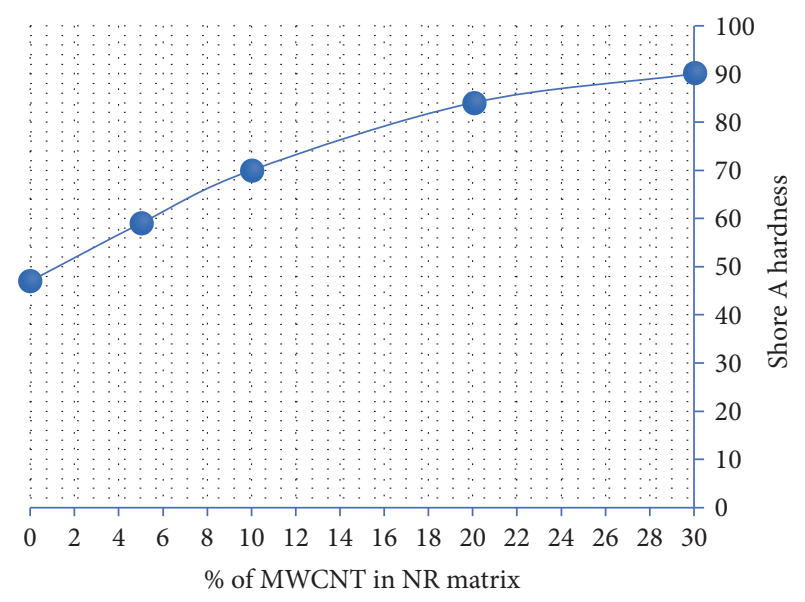

FIGURE 12: Hardness of filled NR nanocomposites.

mechanical properties which is observed upon high load of MWCNTs in NR matrix.

\section{Conclusions}

The aim of this paper is to investigate the effect of high loading of MWCNTs into NR matrix. The samples are prepared with different weight fractions $(5 \%, 10 \%, 20 \%$, and $30 \%)$ of MWCNTs through two-roll mill. Rheology tests are done to measure the scorch time, cure time, minimum torque and maximum torque, and cure rate. A drop of the scorch safety is noticed as a consequence of the addition of MWCNTs in NR matrix. Interestingly, the scorch time is increased on $20 \mathrm{phr}$ and $30 \mathrm{phr}$ samples, regarded as the increase in the process safety. The dumb bell samples as per ASTM D41206a (ISO 37) standard are prepared and tensile tests are conducted in Instron machine. From the results, it is noticed that NR/30 phr MWCNT has the highest tensile strength of $23.38 \mathrm{MPa}$, which is $78.18 \%$ higher than the pure NR. It is also observed from hardness test as per ASTM 2240 that Shore A hardness of $30 \mathrm{phr}$ MWCNT filled NR is 90 , which is about $91.5 \%$ higher than pure NR. It is drastic increase in the mechanical strength and hardness upon increase of the filler weight percentage. Meanwhile, it is observed that the ductility loss and decrease in elongation at break upon filler increase. The elongation at break of 5, 10, 20, and $30 \mathrm{phr}$ composites is observed as $280,173,169$, and 156 , respectively. The tensile strength of the composites is predicted from Halpin-Tsai model and compared with the experimental results. The close agreement of result is observed, particularly at higher loading (30 phr) of filler. SEM, FTIR, and AFM examinations are also conducted for qualitative analysis of the composites. The significant change in IR spectrum and AFM images are observed which is regarded as the good wetting of MWCNTs in NR matrix. The SEM results also show high dispersion of nanofillers and strong interfacial interaction with rubber, which is responsible for overall enhancement in mechanical properties of the nanocomposites. The experimentally measured strain-stress data are used to evaluate nonlinear material constants of extended tube model-a nonlinear hyperelastic material model that well suits the filler reinforced composites. The nonlinear constants are presented for the readers and designers to use them in design and FE analysis.

\section{Conflicts of Interest}

The authors declare that there are no conflicts of interest regarding the publication of this paper.

\section{Acknowledgments}

The authors would like to give special thanks to UCSI University, Malaysia, for the fund support under YSIF, Grant no. YSIF-2015-000033. Also thanks are due to Aerospace Pvt. Ltd., India, for providing them with natural rubber and helping them in preparing nanocomposites.

\section{Supplementary Materials}

Graphical abstract of the research is shown. It depicts the synthesis of MWCNT/NR composite and various characterisation done in the research paper. (Supplementary Materials)

\section{References}

[1] N. Elango and A. A. M. Faudzi, "A review article: investigations on soft materials for soft robot manipulations," The International Journal of Advanced Manufacturing Technology, vol. 80, no. 5-8, pp. 1027-1037, 2015.

[2] N. Rattanasom, T. Saowapark, and C. Deeprasertkul, "Reinforcement of natural rubber with silica/carbon black hybrid filler," Polymer Testing, vol. 26, no. 3, pp. 369-377, 2007.

[3] D. Qian, E. C. Dickey, R. Andrews, and T. Rantell, "Load transfer and deformation mechanisms in carbon nanotube-polystyrene composites," Applied Physics Letters, vol. 76, no. 20, pp. 28682870, 2000.

[4] B. Safadi, R. Andrews, and E. A. Grulke, "Multiwalled carbon nanotube polymer composites: synthesis and characterization of thin films," Journal of Applied Polymer Science, vol. 84, no. 14, pp. 2660-2669, 2002. 
[5] M. S. P. Shaffer and A. H. Windle, "Fabrication and characterization of carbon nanotube/poly(vinyl alcohol) composites," Advanced Materials, vol. 11, no. 11, pp. 937-941, 1999.

[6] C. Pirlot, I. Willems, A. Fonseca, J. B. Nagy, and J. Delhalle, "Preparation and characterization of carbon nanotube/polyacrylonitrile composites," Advanced Engineering Materials, vol. 4, no. 3, pp. 109-114, 2002.

[7] R. Andrews, D. Jacques, M. Minot, and T. Rantell, "Fabrication of carbon multiwall nanotube/polymer composites by shear mixing," Macromolecular Materials \& Engineering, vol. 287, no. 6, pp. 395-403, 2002.

[8] P. Pötschke, T. D. Fornes, and D. R. Paul, "Rheological behavior of multiwalled carbon nanotube/polycarbonate composites," Polymer Journal, vol. 43, no. 11, pp. 3247-3255, 2002.

[9] G. Viswanathan, N. Chakrapani, H. Yang et al., "Single-step in situ synthesis of polymer-grafted single-wall nanotube composites," Journal of the American Chemical Society, vol. 125, no. 31, pp. 9258-9259, 2003.

[10] W. Wu, S. Zhang, Y. Li et al., "PVK-modified single-walled carbon nanotubes with effective photoinduced electron transfer," Macromolecules , vol. 36, no. 17, pp. 6286-6288, 2003.

[11] W. D. Zhang, L. Shen, I. Y. Phang, and T. Liu, "Carbon nanotubes reinforced nylon- 6 composite prepared by simple melt-compounding," Macromolecules , vol. 37, no. 2, pp. 256259, 2004.

[12] W. Chen, X. Tao, and Y. Liu, "Carbon nanotube-reinforced polyurethane composite fibers," Composites Science and Technology, vol. 66, no. 15, pp. 3029-3034, 2006.

[13] F. H. Gojny, M. H. G. Wichmann, U. Köpke, B. Fiedler, and K. Schulte, "Carbon nanotube-reinforced epoxy-composites: enhanced stiffness and fracture toughness at low nanotube content," Composites Science and Technology, vol. 64, no. 15, pp. 2363-2371, 2004.

[14] R. Gulotty, M. Castellino, P. Jagdale, A. Tagliaferro, and A. A. Balandin, "Effects of functionalization on thermal properties of single-wall and multi-wall carbon nanotube-polymer nanocomposites," ACS Nano, vol. 7, no. 6, pp. 5114-5121, 2013.

[15] K. Takeuchi, T. Noguchi, H. Ueki et al., "Improvement in characteristics of natural rubber nanocomposite by surface modification of multi-walled carbon nanotubes," Journal of Physics and Chemistry of Solids, vol. 80, pp. 84-90, 2015.

[16] S. D. S. Pinto and M. C. Rezende, "Electromagnetic, morphological, and electrical characterization of POMA/Carbon nanotubes-based composites," Journal of Nanomaterials, vol. 2017, Article ID 1989785, 9 pages, 2017.

[17] J. Li, "Multiwalled carbon nanotubes reinforced polypropylene composite material," Journal of Nanomaterials, vol. 2017, Article ID 2171356, 5 pages, 2017.

[18] S. Phomrak and M. Phisalaphong, "Reinforcement of natural rubber with bacterial cellulose via a latex aqueous microdispersion process," Journal of Nanomaterials, vol. 2017, Article ID 4739793, 9 pages, 2017.

[19] C. Medina, E. Fernandez, A. Salas et al., "Multiscale characterization of nanoengineered fiber-reinforced composites: effect of carbon nanotubes on the out-of-plane mechanical behavior," Journal of Nanomaterials, vol. 2017, Article ID 9809702, 9 pages, 2017.

[20] M. A. Tarawneh, S. H. A. R. Rasid, S. Y. Y. S. Bahri, A. R. S. Ehnoum, K. Z. Ka, and L. Y. Seng, "Mechanical properties of thermoplastic natural rubber (TPNR) reinforced with different types of carbon nanotube," Sains Malaysiana, vol. 40, no. 7, pp. 725-728, 2011.
[21] A. A. Azira, D. H. A. I. Hassim, A. B. Suriani, and M. R. Mahmood, "Characterization of Multi-Walled Carbon Nanotubes/Natural Rubber Nanocomposite by Wet Mixing Method," Nano Hybrids, vol. 1, pp. 81-97, 2012.

[22] L. Bokobza, "Multiwall carbon nanotube-filled natural rubber: electrical and mechanical properties," Express Polymer Letters, vol. 6, no. 3, pp. 213-223, 2012.

[23] J. C. Halpin and J. L. Kardos, "The Halpin-Tsai equations: a review, Polymer Engineering \& Science, vol. 16, no. 5, pp. 344352, 1976.

[24] M. Mooney, "A theory of large elastic deformation," Journal of Applied Physics, vol. 11, no. 9, pp. 582-591, 1940.

[25] R. W. Ogden, "Large deformation isotropic elasticity on the correlation of theory and experiment for incompressible rubber like solids," Proceedings of the Royal Society of London A: Mathematical A, vol. 326, no. 1567, pp. 565-584, 1972.

[26] E. M. Arruda and M. C. Boyce, "A three-dimensional constitutive model for the large stretch behavior of rubber elastic materials," Journal of the Mechanics and Physics of Solids, vol. 41, no. 2, pp. 389-412, 1993.

[27] O. H. Yeoh, "Some forms of the strain energy function for rubber," Rubber Chemistry and Technology, vol. 66, no. 5, pp. 754-771, 1993.

[28] A. N. A. Gent, "A new constitutive ralation for rubber," Rubber Chemistry Technology, vol. 69, no. 1, pp. 59-61, 1996.

[29] L. R. G. Treloar, The Physics of Rubber Elasticity, Oxford University Press, Oxford, UK, 1975.

[30] K. Wan-Doo, K. Wan-Soo, K. Dong-Jin, W. Chang-Soo, and L. Hak-Joo, "Mechanical testing and nonlinear material properties for finite element analysis of rubber components," Transactions of the Korean Society of Mechanical Engineers, vol. 28, no. 6, pp. 848-859, 2015.

[31] N. Elango and R. Marappan, "Analysis on the fundamental deformation effect of a robot soft finger and its contact width during power grasping," The International Journal of Advanced Manufacturing Technology, vol. 52, no. 5-8, pp. 797-804, 2011.

[32] N. Elango, A. A. M. Faudzi, A. Hassan, and M. R. M. Rusydi, "Experimental investigations of skin-like material and computation of its material properties," International Journal of Precision Engineering and Manufacturing, vol. 15, no. 9, pp. 1909-1914, 2014.

[33] N. Elango, M. Faudzi, A. Athif et al., "Determination of nonlinear material constants of RTV silicone applied to a soft actuator for robotic applications," Key Engineering Materials, vol. 594, pp. 1099-1104, 2013.

[34] M. Kaliske and G. Heinrich, "An extended tube-model for rubber elasticity: statistical-mechanical theory and finite element implementation," Rubber Chemistry and Technology, vol. 72, no. 4, pp. 602-632, 1999.

[35] R. Behnke and M. Kaliske, "The extended non-affine tube model for crosslinked polymer networks: physical basics, implementation, and application to thermomechanical finite element analyses," in Designing of Elastomer Nanocomposites: From Theory to Applications, K. W. Stöckelhuber, A. Das, and M. Klüppel, Eds., vol. 275 of Advances in Polymer Science, pp. 1-70, Springer, 2016.

[36] G. Marckmann and E. Verron, "Comparison of hyperelastic models for rubber-like materials," Rubber Chemistry and Technology, vol. 79, no. 5, pp. 835-858, 2006.

[37] Y. Gorash, T. Comlekci, and R. Hamilton, "CAE-Based application for identification and verification of hyperelastic parameters," Proceedings of the Institution of Mechanical Engineers, Part 
L: Journal of Materials: Design and Applications, vol. 231, no. 7, pp. 611-626, 2015.

[38] R. Behnke, M. Kaliske, and M. Klüppel, “Thermo-mechanical analysis of cyclically loaded particle-reinforced elastomer components: experiment and finite element simulation," Rubber Chemistry and Technology, vol. 89, no. 1, pp. 154-176, 2016.

[39] F. M. Blighe, W. J. Blau, and J. N. Coleman, "Towards tough, yet stiff, composites by filling an elastomer with single-walled nanotubes at very high loading levels," Nanotechnology, vol. 19, no. 41, Article ID 415709, 2008. 

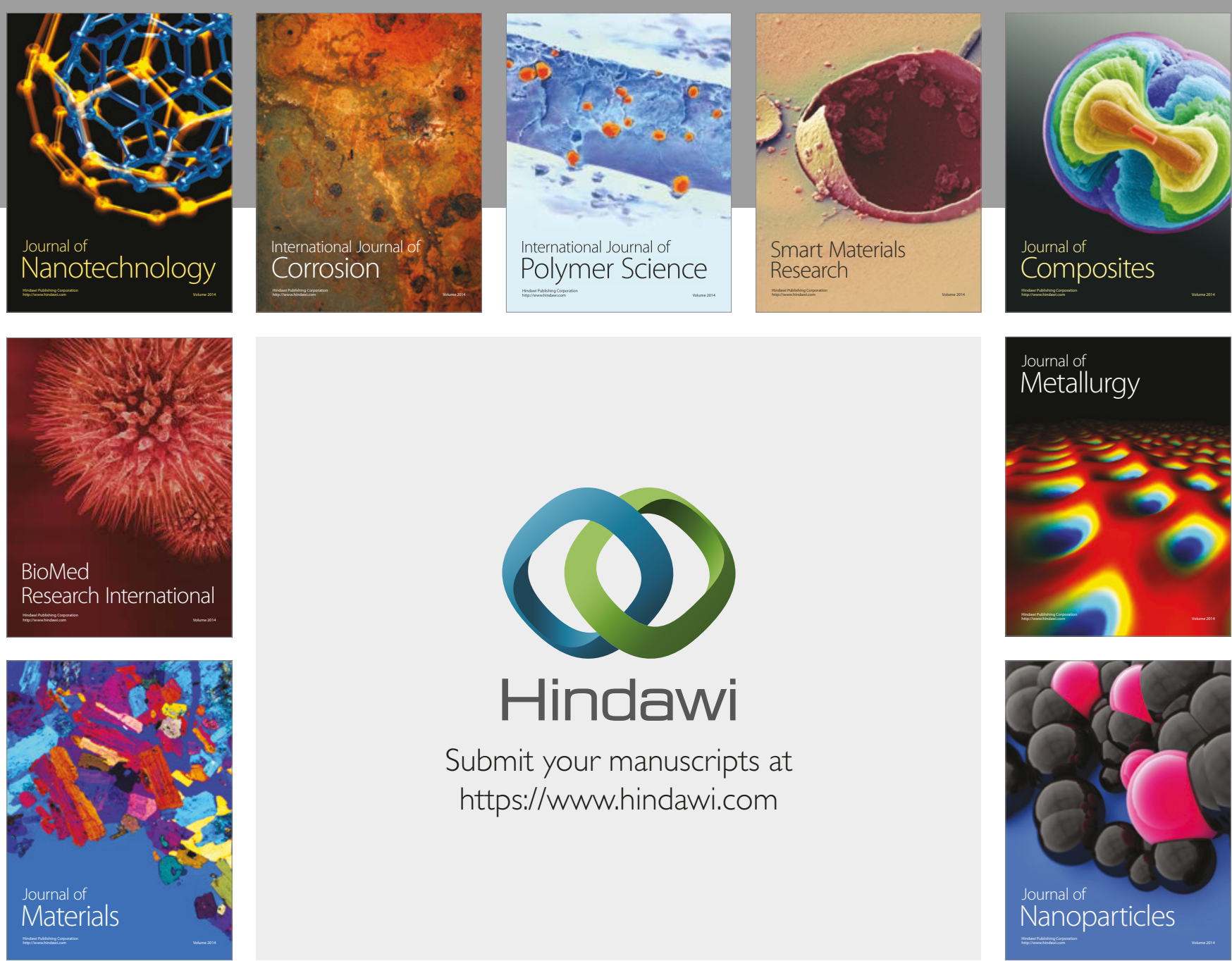

\section{Hindawi}

Submit your manuscripts at

https://www.hindawi.com
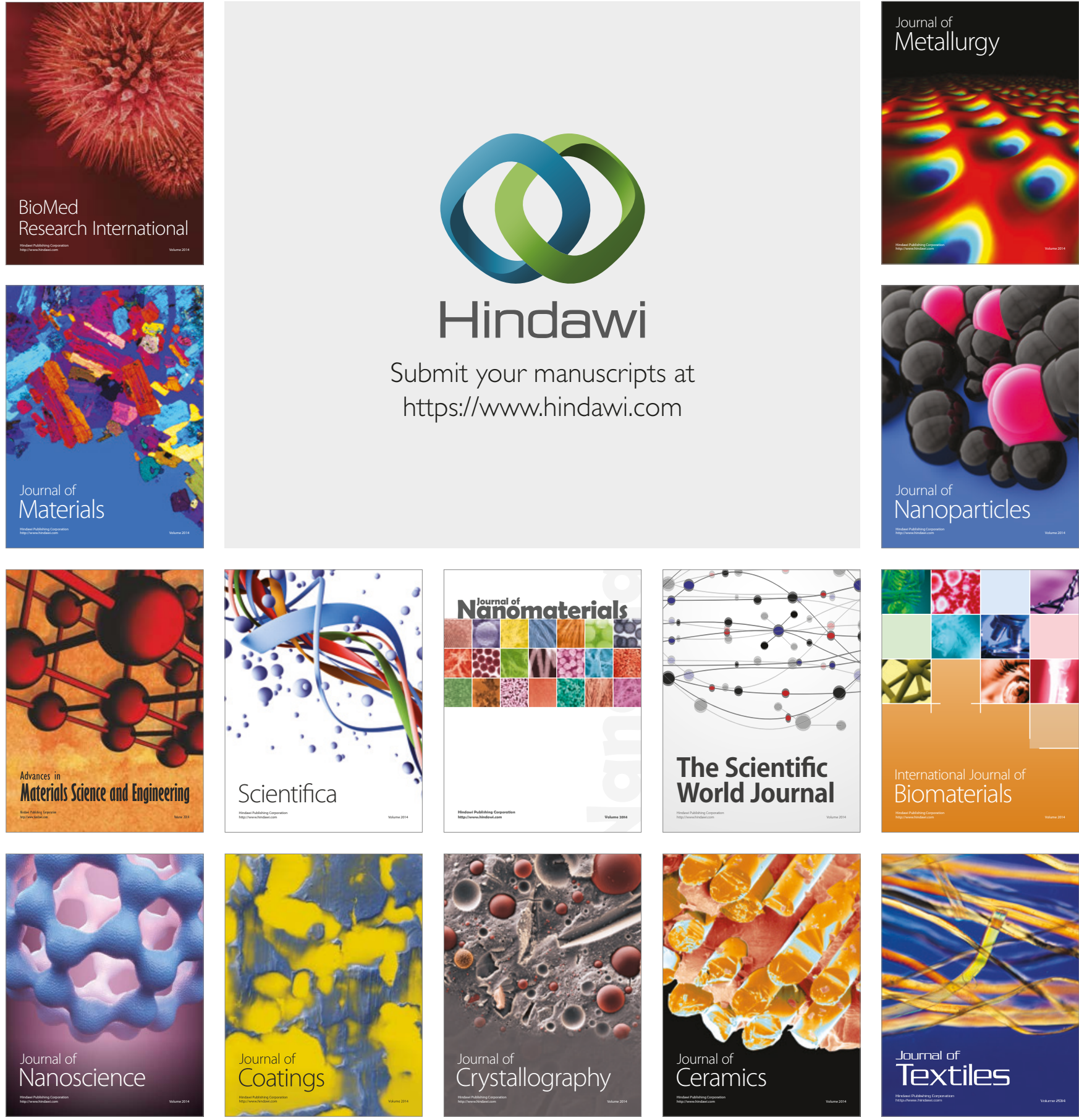

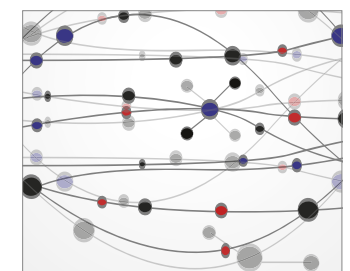

The Scientific World Journal
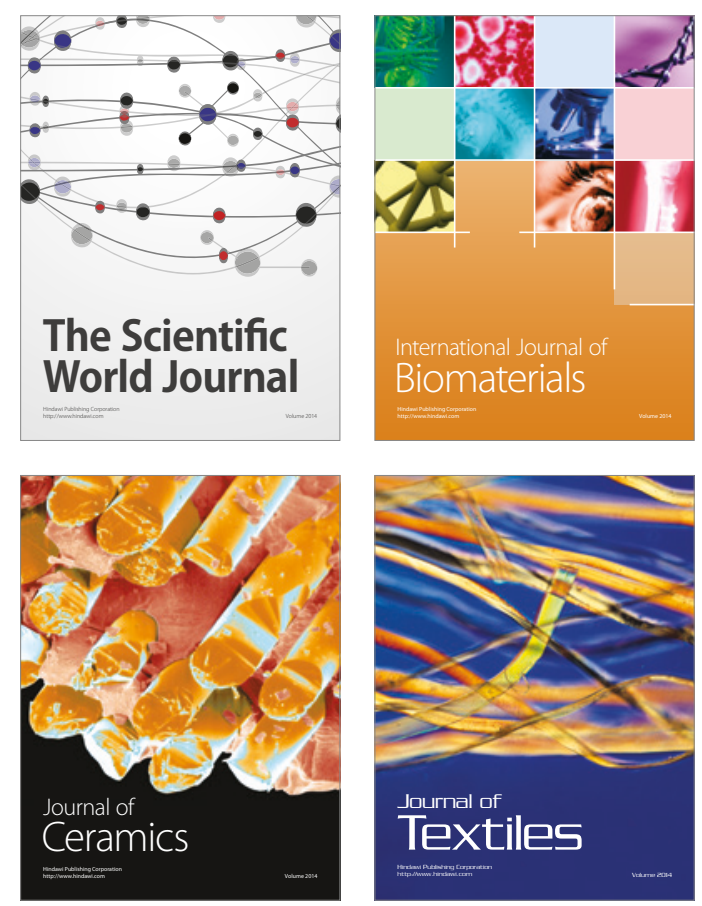